\title{
Presidential Address: Challenges Facing the American Pediatric Society in 1982. Annual Meeting, Washington, D.C.
}

\author{
HENRY L. BARNETT, M.D. ${ }^{5}$ \\ Department of Pediatrics, Albert Einstein College of Medicine of Yeshiva University [Professor Emeritus] and The \\ Children's Aid Society, [Medical Director] New York, New York, U.S.A.
}

This has been an eventful year for academic medicine, for children and their families, for the country, and for the world. Academic medicine has been challenged by reduced funding for biomedical research and education, by increased external political influences on it, by reimposition of limitations on freedom of exchange with scientists from some other countries, and by strict enforcement of the rule known as "A-21" that requires scientists who receive Federal grants to make impossible estimates and therefore inaccurate accounts of all their time by listing the percentages devoted to teaching, advising, research on their grant, and any other activities.

The welfare of children and their families, especially the poor, is being threatened by cruel cutbacks and even eliminations of social programs adversely affecting the health and dignity of children, the most recent of which is the proposed regulation that requires federally funded family planning clinics to notify parents of girls age 17 or younger when they prescribe contraceptive drugs or devices.

The country and the whole world are facing the greatest menace of all, the threat of nuclear war.

As individuals we have a large stake in seeking solutions to these challenges and threats. As physicians, and especially as academic pediatricians, we have unique responsibilities for some of them, but all of them must be studied and understood in order for each of us to select and work for the solutions we consider the wisest.

Challenges to the American Pediatric Society, the subject of my Presidential Address, are of a very different order of magnitude of importance, but they exist, and they, too, must be identified and solutions sought.

One challenge, as I see it, comes from members of the academic societies of internal medicine and obstetrics. The increasing evidence that many disorders manifested first in adulthood have their origins in childhood or even prenatally (1) has stimulated widespread interest among academic internists in developmental clinical medicine and in human developmental biology. Until a few years after World War II, the whole period of fetal growth and development was essentially ignored in obstetrical teaching and research, and the care of newborns was gratefully delegated to the pediatrician. In contrast, current research in academic obstetrics is focusing increasingly on growth and development of the fetus and newborn (4).

Why do these new interests of academic internists and obstetricians constitute challenges to the APS? For the most part they are welcomed, because their increased awareness of the valuable scientific potential of studying human developmental biology brings larger numbers of skilled investigators into areas of clinical and biomedical science, which previously made pediatric research unique. They also contribute to recognition of the important concept that human development is a circular process with no fixed starting point, and thus help dispel the long held scientifically harmful misconception that it begins at birth
However, I do have some concerns. The first is that on some occasions internists and obstetricians tend to approach these problems by reinventing the wheel, and thereby fail to use increasingly scarce research funds and scientific talent as productively as possible. A more serious concern is that if their new interests involve clinical investigation and the care of infants, children, and their families, the necessary psychosocial understanding and support provided by most pediatric investigators may be neglected. Neither of these problems is unsolvable - or at least I think not. Finally, I have some concern that these awakenings may unfortunately strengthen the misconception that, through engaging in developmental research, an internist or obstetrician becomes qualified to head a department of pediatrics.

The second challenge to our society is of a different nature. It comes from within academic pediatrics, and represents, I believe, developmental processes that are both inevitable and invaluable. They stem from the need for maximum exchange of information and ideas among colleagues in specific academic pediatric disciplines and represent two distinct groups that can be defined as, one, the highly specialized, developmental biomedical system specialists, and two, specialists in psychosocial aspects of pediatrics, in medical care evaluation, and in adolescent medicine. The research being done by all of these specialists are within welldefined areas of developmental human biology and clinical pediatrics. The conflict arises therefore, not in the nature of their research, but rather in the question of with whom they identify most closely, or, more practically, with whom they should meet. These problems become increasingly critical as funds for attending national meetings become more and more ephemeral. I have been distressed by the number of members of our Society who told me that they could not chair specialty sessions because they could not afford to attend this meeting.

Can the needs of these groups for communication and scientific exchange be met fully through the annual meetings of the APS and the SPR? The answer obviously is no, because independent societies for many pediatric biomedical subspecialties, for academic ambulatory pediatrics, and for adolescent medicine have been founded and are flourishing. The unanswered questions, then, are how these societies relate to the APS and SPR, and, more frankly, what remaining purposes the APS and SPR serve.

There are subtilities in these complex questions that do not permit analytic answers. I have chosen rather to consider, as thoughtfully as I can, my own observations as an active participant in the scene. My experience with internists has been mostly with nephrologists and through membership in their Societies, as well as in the Society for Clinical Investigation and the Association of American Physicians. My experience with highly specialized pediatric biomedical system specialists has been in pediatric nephrology and membership in their Societies. Finally, although I am not a member of the Ambulatory Pediatric Association, some of my "best friends" are. In addition, in my present position as Medical Director of The Children's Aid Society, I am responsible for the 
delivery and evaluation of the effectiveness of primary medical care of foster children, and for health maintenance of headstart and older children, including adolescents, in after school neighborhood programs.

Let me give some specific examples of these problems that have developed during the past years and describe the questions they pose. During the years that the APS and SPR met separately from the internists, the other academic pediatric societies could hold their annual meeting on the free day preceding the meetings of the APS and SPR. Now that we are meeting again with the internists in order to bridge our mutual biomedical interests, these pediatric subspecialty societies, if they are to meet with us, must have an evening meeting, or meet the day following our last meeting. A second example: the internists now have a Society for Research and Education in Primary Care Internal Medicine, and the APA has requested that every third year our first specialty sessions adjacent to the meeting of the internists be devoted to psychosocial and clinical care evaluation research so that their mutual interests can be bridged.

These may appear to be housekeeping details, but they reflect much deeper questions and concerns. Would pediatric gastroenterologists who can attend only one national meeting a year, gain more by meeting with the American Gastroenterologic Society than with the APS and SPR? Would members of the APA gain greatest benefit from attending a single national meeting at the time of the American Public Health Association, or from a freestanding meeting as they have considered seriously?

If the answer to these questions is "yes," I must ask again, who will attend the meetings of the APS and SPR and why? Before making this assumption and answering the questions, let me explore some of the more substantive issues involved.

Over the past several years I have thought, and even argued occasionally in public (2), that primary medical care and tertiary medical care are becoming increasingly divergent. This assertion is not earth shaking and usually is readily accepted by professionals in each field until it is examined more closely and some of its implications and consequences are revealed. Although it involves all aspects of medicine, including education, research, and practice, I want to examine it in terms of education and primarily research. The ifuestion of when the educational track for pediatricians preparing for either primary care or for specialty care and research should diverge is being actively considered by many committees, heads of pediatric departments and program directors. I would say only, without defending the arguments here, that I believe training must diverge before the completion of 3 years of general pediatric residency.

It is of interest that in the original Constitution of the American Pediatric Society, drafted at the organization meeting in September, 1888, Article I states: "The Society has for its object the advancement of the Physiology, Pathology, and Therapeutics of Infancy and Childhood." The invitation to join the Society specified its aim to be "the study of diseases in children" (3). This definition suggests that membership in the APS would be limited to academic pediatricians whose research was on children's diseases, which, at that time, were considered to be almost exclusively biomedical. This statement of policy was modified in 1950, and in its present form states that the object of the Society is "to bring together men and women for the advancement of the study of children and their diseases, for the prevention of illness and the promotion of health in childhood, for the promotion of education and research, and to honor those who, by their contributions to pediatrics, have aided in its advance."

Thus, we all qualify under these new rules. However, again, I believe research in primary and tertiary care have become so divergent that they are rapidly becoming separate disciplines, or, more accurately, discrete disciplines within the same profession. Both disciplines require sound scientific and medical education. However, the extent and intensity of training in the underlying basic sciences required for the two, defined broadly as either biomedical research or psychosocial and medical care evaluation research, are quite different.

Training for these disciplines and productive research and teaching in each of them has become extremely extensive, complex, and all encompassing. It is understandable, therefore, given the opportunity to attend a single annual national meeting to exchange concepts and methods for research and teaching, most investigators might choose to meet with colleagues in their own specific scientific field. The effect of aldosterone in the cortical collecting duct is discussed more fruitfully among pediatric nephrologists than it would be with adolescent physicians investigating the incidence of depression in adolescence. In an earlier version of this address, I had used for the latter example, the study of human sexuality, but I have been reminded that even pediatric nephrologists are interested in human sexuality. These statements are not meant to be entirely facetious. Serious academic pediatric immunologists need to meet together, and so do equally serious investigators and teachers of methods to achieve better utilization of available systems for health care for infants and children.

My answer, then, is an unequivocal yes: specialty groups within academic pediatrics, whether based primarily on biomedical or psychosocial or clinical care evaluation, do need their own meetings and also to have interchanges with other scientists in their specialties. My conviction is even stronger, however, that some of their limited time and resources for attending annual national meetings must be spent by academic pediatricians at the noncategorical meetings of the APS and SPR.

Practically, unless larger facilities are developed and better methods of communication devised, or unless there is an increase in the availability of funds for attending scientific meetings, it is clear that for each of us, priorities will have to be weighed carefully and decisions made. Except for 1984 and 1987, when we meet by ourselves in San Francisco, we are booked unalterably to meet with the internists in Washington until 1988. Thus, during the next two years, during which time a decision about meetings beginning in 1988 will need to be made, we will have had one more meeting with the internists and one by ourselves. We had our first formal joint session with the internists this year and we will be able to schedule the meeting in 1984 to meet more fully the needs of all of the academic pediatric Societies. During these meetings, specific attention to the problems I am raising should help us decide about future meetings.

I myself fought against separating from the internists in 1971, and $I$ favored rejoining them in 1981. If we separate again after 1987, I think we would be forfeiting a very valuable scientific asset. Several designs for the structure of joint meetings that, through various compromises, could encompass the major goals of all of the Societies have been suggested, and they should continue to be considered. However, if a choice has to be made, as I think it will, between meeting with the internists or meeting separately after 1987, my vote would be unequivocably to keep the meetings of all of the academic pediatric societies together.

Why this change of mind-or is it of heart-or both? What are the most compelling reasons? I believe they are the following:

The underlying aspect of academic pediatric research and teaching emphasized by Kretchmer in his Presidential Address in 1980, is human development, defined as time dependent changes in structures and functions. Despite the new interest of internists and obstetricians in development, it is not their central interest. In contrast, it is the basic interest among all of our disciplines that otherwise are widely disparate. This argument is not just theoretical or rhetorical. For example, in the postdoctoral research training program in human development biology that I directed for 7 years, we achieved effective interdisciplinary interest and participation among people in many diverse pediatric disciplines through a series of seminars on subjects of mutual interest. One of the most successful considered the theoretical and practical problems of selecting standards of reference and interpreting their application in developmental research. Developmental behavioral scientists found common problems with developmental enzymologists and they learned from one another.

Second, system specialists tend to become very narrow and even chauvinistic. A nephrologist stuck in the cortical collecting duct for several years may begin to look with disdain even at his colleagues in the distal portion of the ascending loop. Another 
indication of this type of tunnel vision was demonstrated in the postdoctoral research training program I mentioned that included trainees with both M.D.'s and PhD's. When told of the requirement that to continue to be supported, the fellow must attend the weekly interdisciplinary conference, the applicant with a $\mathrm{PhD}$ often expressed enthusiasm for hearing about developmental research others were doing, whereas the MDs too frequently implied they would come, but were reluctant to leave their research laboratories.

Third, societies of special interest tend to become inbred through the teacher-student-fellow-teacher sequence and risk losing some of their capacity for self-criticism and even insights that lead to innovative advances. This threat applies to specialists in ambulatory pediatrics as well as to biomedical specialists. Pediatricians engaged in psychosocial or medical care evaluation research talking only with one another are likely to accept too readily the limitations imposed on their research by the larger number of uncontrollable variables. Attending meetings at which the less complicated research strategies and designs of the biomedical specialists are presented can serve to lessen this unproductive attitude. Conversely, while continuing their research into more and more basic and detailed biomedical mechanisms, biomedical specialists may be stimulated in some instances to ask more complex questions concerning multifactorial physiologic functions as they hear research reports of their colleagues in psychosocial and medical care evaluation research. As educated adults in our present society, and especially as physicians and pediatricians, we owe it to our students, our institutions, and to our patients and their families to be knowledgeable about scientific advances in general, and especially about those in medicine and biology.

Fourth, system specialists meeting only with one another sometime forget that systems are interrelated, and that only when they are combined do they become children and families. In addition, necessary deep immersion in one area of clinical science may tend to obscure many of the early motives for seeking medical training, and the satisfactions of being a physician. Meetings of the APS and SPR serve to remind them of these earlier goals and yearnings.

Finally, one of the rare privileges of a physician, and especially one in academic medicine, is the opportunity to make productive and satisfying changes in career. I may be overestimating this feature because I have recently moved from a purely academic career of over 40 years to the position of medical director of a social service agency. Meetings of the APS and SPR provide exposure to colleagues in other disciplines that may stimulate exciting changes in careers. Such changes usually occur later in ones professional life, and may be part of the aging process as in the sad story of two elderly friends who had played golf together for many years. One told his friend he could play no longer because he couldn't see the ball after he hit it. The other insisted that he would watch the ball for his friend. After teeing off, the first asked the second whether he had seen his ball land. The second replied that he had seen it, but he couldn't remember where it was.

To return to my Address, we must ask how can the legitimate needs for national meetings of the various special pediatric groups, the contact with other academic Societies, and the continuing valuable roles of the meetings of the APS and the SPR be met. The major obstacles are money, time and space. It is likely during the next years that many members of the APS and SPR will be able to afford to attend only one national meeting each year. This year the combined meetings of the academic internists and pediatricians extend from Saturday, May 8th, through Saturday, May 15th, 1982, a period extended by travel for some to a total of 10 or more days. There are no meeting facilities in the country that provide space for the simultaneous attendance of members and guests of all of these Societies, exceeding 20 in number and growing.
What, then, is the answer? Fundamentally I believe it is that the members of these various academic pediatric societies must have more knowledge of and respect for the purposes and aspirations of the others. Paying lip service, which many of us do, is not enough. Members of the Ambulatory Pediatric Association must realize that investigators in the American Society for Pediatric Nephrology, while concentrating in their research on the collecting duct, are also participating in the care of children with renal disease, and most of them with great sensitivity to the psychosocial, educational, and financial needs of the children and their families. Conversely, members of the biomedical specialty societies must appreciate that the Ambulatory Pediatric Association was formed to promote research as well as service and especially teaching in pediatric clinical care evaluation. Research in this field has a scientific base in epidemiology, psychology, and sociology, and what Alvin Feinstein yesterday described as clinimetrics. However, it must be understood and accepted that the large number of variables involved in most of their inquiries make the research designs and interpretations far more difficult, not just "softer." If the questions they posed were as simple as those of the biomedical scientists, they could probably answer them as readily, but unfortunately easily answered questions in these disciplines tend to be trivial.

From my long and treasured participation in the meetings of most of these academic societies, let me conclude with the following thoughts. I hope that the issues I have raised will persuade the academic pediatric societies to continue to meet together; I hope that the values I have attributed to meetings of the APS and SPR will continue to exist, and that one of your children or grandchildren will write Volume II of Faber and McIntosh's History of the American Pediatric Society, covering the years 1965-2043.

I consider it a high honor to have served as President of the American Pediatric Society and I have enjoyed it. When I was elected, I believe members of both the American Society of Pediatric Nephrology and of the Ambulatory Pediatric Association thought that at last their objectives would be understood and some of their problems solved. I fear I have disappointed both groups in regard to solving their problems. However, I have, I hope, supported not only their objectives, but perhaps even more critically in the future if not now, those of the APS and SPR, which I believe must continue to have the highest priority.

Let me close by returning to the broader challenges facing academic medicine, children and their families, the country and the world. The purposes of the American Pediatric Society have been, since its founding, and I believe should continue to be, academic and scientific. However, the gravity of these present challenges and threats, especially that of nuclear war is so great, not only to children, but to all mankind that for us, as a Society, not to work for solutions for them, would be to forsake our responsibility as individuals and as academic pediatricians. I am heartened that at its business meeting yesterday, the Society unanimously passed a resolution calling upon the United States and the U.S.S.R. to stop the nuclear arms race and I urge all of us to support it vigorously.

\section{REFERENCES AND NOTES}

1. Barktop, D. (Ed.) Pediatric Implications for Some Adult Disorders The Fellowship of Postgraduate Medicine, London, 1977.

2. Barnett, H. L. A Pediatricians View in the Current Status and Future of Academic Obstetrics. (Eds. Bowers, J. Z., and Purcell, E. F.), Josiah Macy, Jr., Foundation, $1980, \mathrm{p} 30$.

3. Faber, H. K., and McIntosh, R. History of the American Pediatric Society 18871965, McGraw Hill Book Company, New York, 1966, p 9.

4. Pritchard, J. A., The Impact of Perinatology on Academic Obstetrics in The Current Status and Future of Academic Obstetrics (Eds. Bowers, J. Z., and Purcell, E. F.) Josiah Macy, Jr., Foundation, 1980, p 150

5. Request for reprints: Dr. Henry L. Barnett, The Children's Aid Society, $150 \mathrm{E}$. 45th St., New York, NY 10017 